\title{
Substrate Cycling between Gluconeogenesis and Glycolysis in Euthyroid, Hypothyroid, and Hyperthyroid Man
}

Gerald I. Shulman, Paul W. Ladenson, Marta H. Wolfe, E. Chester Ridgway, and Robert R. Wolfe

Diabetes Unit, and Thyroid Unit, Massachusetts General Hospital, Boston, Massachusetts 02114;

and The Shriners Burns Institute, Boston, Massachusetts 02114

\begin{abstract}
Substrate, or futile cycles, have been hypothesized to be under hormonal control, and important in metabolic regulation and thermogenesis. To define the role of thyroid hormones in the regulation of substrate cycling in glycolysis and gluconeogenesis, we measured rates of cycling in normal $(n=4)$, hypothyroid $(n=5)$, and hyperthyroid $(n=5)$ subjects employing a stable isotope turnover technique. Glucose labeled with deuterium at different positions (2- $\mathrm{D}_{1}-, 3-\mathrm{D}_{1}-$, and $6,6-\mathrm{D}_{2}-$-glucose) was given as a primed-constant infusion in tracer doses, and arterialized plasma samples were obtained and analyzed by gas-chromatography mass-spectrometry for the steady state enrichment of glucose that was labeled at the various positions. The rate of appearance (Ra) was then calculated for each isotopic tracer. The difference between the $R \mathbf{a}$ determined by 2-D -glucose $\left(\mathbf{R a}_{2}\right)$ and the $\mathbf{R a}$ determined by 3- $\mathrm{D}_{1}$-glucose $\left(\mathrm{Ra}_{3}\right)$ represents the substrate cycling rate (SCR) between glucose and glucose6-phosphate. The difference between the $\mathrm{Ra}$ determined by 3$D_{1}$-glucose $\left(R_{3}\right)$ and the $\mathrm{Ra}$ determined by $6,6-\mathrm{D}_{2}$-glucose $\left(\mathrm{Ra}_{6}\right)$ represents the SCR between fructose-6-phosphate and fructose-1,6-diphosphate. The difference betweet $\mathbf{R a}_{2}$ and $\mathbf{R a}_{6}$ represents the combined SCR of both cycles.

In normal subjects (serum thyroxine $\left[T_{4}\right]=8.4 \pm 1.2 \mu \mathrm{g} / \mathrm{dl}$ (all expressions, mean $\pm S D$ ), $n=4$ ), the rates of appearance for $\mathrm{Ra}_{2}, \mathrm{Ra}_{3}$, and $\mathrm{Ra}_{6}$ were $3.23 \pm 0.56,2.64 \pm 0.50$, and $2.00 \pm 0.27 \mathrm{mg} / \mathrm{kg} \cdot \mathrm{min}$, respectively, whereas those in the hypothyroid subjects $\left(\mathrm{T}_{4}=1.0 \pm 0.8 \mu \mathrm{g} / \mathrm{dl} ; n=5\right)$ were $1.77 \pm 0.56(P<0.01), 1.52,1.57 \pm 0.31(P<0.05) \mathrm{mg} / \mathrm{kg} \cdot \mathrm{min}$ respectively. Conversely, the rates of appearance for $\mathbf{R} \mathbf{a}_{2}$ and $R a_{6}$ in the hyperthyroid subjects $\left(T_{4}=23.9 \pm 3.6 \mu \mathrm{g} / \mathrm{dl}\right)$ were $3.94 \pm 0.43(P<0.05)$ and $2.54 \pm 0.22(P<0.02)$, respectively, compared with the normal subjects. On the basis of these data, we noted that the normal subjects had a combined SCR of $1.23 \pm 0.35 \mathrm{mg} / \mathrm{kg} \cdot \mathrm{min}$. In contrast, the hypothyroid patients had a significantly decreased combined SCR, $0.20 \pm 0.54 \mathrm{mg}$ /
\end{abstract}

An abstract of this work has been presented at the American Thyroid Association Meetings, 1983, New Orleans, LA, and at a meeting of the American Chemical Society, 1984, Washington, DC.

Dr. Shulman's present address is Department of Molecular Biophysics and Biochemistry, Yale University, New Haven, CT 06511. Dr. Wolfe's present address is The Shriners Burns Institute and the University of Texas, Medical Branch, Galveston, TX 77550. Dr. Ladenson is a Teaching and Research Scholar of the American College of Physicians. Address correspondence to Dr. Wolfe.

Received for publication 6 September 1984 and in revised form 8 April 1985.

J. Clin. Invest.

(c) The American Society for Clinical Investigation, Inc.

0021-9738/85/08/0757/08 $\$ 1.00$

Volume 76, August 1985, 757-764 $\mathrm{kg} \cdot \min (P<0.02)$. The hyperthyroid patients had a combined SCR of $1.39 \pm 0.23 \mathrm{mg} / \mathrm{kg} \cdot \min (P<\mathrm{NS})$.

To determine whether these cycles responded to thyroid hormone treatment, these same hypothyroid subjects were acutely treated for 1 wk with parenteral $50 \mu \mathrm{g} / \mathrm{d}$ sodium Ltriiodothyronine and chronically with $100-150 \mu \mathrm{g} / \mathrm{d} \mathrm{L}$-thyroxine. After $7 \mathrm{~d}$, their mean oxygen consumption rate and carbon dioxide production rate increased significantly from $102 \pm 13$ $\mu \mathrm{mol} / \mathrm{kg} \cdot \mathrm{min}$, to $147 \pm 34 \mu \mathrm{mol} / \mathrm{kg} \cdot \min (P<0.05)$, and from $76 \pm 13 \mu \mathrm{mol} / \mathrm{kg} \cdot \min$ to $111 \pm 19 \mu \mathrm{mol} / \mathrm{kg} \cdot \min (P<0.05)$, respectively. The combined SCR $\left(\mathbf{R a}_{2}-\mathbf{R a}_{6}\right)$ remained unchanged at $0.07 \pm 0.37 \mathrm{mg} / \mathrm{kg} \cdot \mathrm{min}$. However, after $6 \mathrm{mo}$ of oral L-thyroxine therapy $\left(T_{4}=9.5 \pm 1.4 \mu \mathrm{g} / \mathrm{dl}\right)$ the treated hypothyroid patients had increased their combined SCR $\left(\mathbf{R a}_{2}\right.$ - $\left.R \mathbf{a}_{6}\right)$ to $0.86 \pm 0.23 \mathrm{mg} / \mathrm{kg} \cdot \min (P<0.02)$, a value not significantly different from the combined SCR of normal subjects.

We conclude that substrate cycling between glucose and glucose-6-phosphate and between fructose-6-phosphate and fructose-1,6-diphosphate occurs in man and is affected by thyroid hormone. Substrate cycles may represent a mechanism by which thyroid hormone alters the sensitivity of certain reactions to metabolic signals.

\section{Introduction}

A substrate, or futile cycle, occurs when two opposing nonequilibrium reactions, catalyzed by separate enzymes, operate simultaneously, with a net result of heat production by hydrolysis of ATP. These cycles may be important in the sensitivity and flexibility of metabolic regulation (1-4). It has also been hypothesized that substrate cycles are under hormonal control and that they play a role in the regulation of body weight and thermogenesis (2). Whereas the existence of such cycles has been demonstrated to occur in vitro and in several in vivo studies $(3,4)$, their existence and potential for hormonal regulation in man has not been well established. Therefore, the goals of these experiments were to determine: $(a)$ whether the hepatic substrate cycles of glycolysis and gluconeogenesis were detectable in normal man; $(b)$ whether their activities were modified in the hypothyroid and hyperthyroid states; and (c) whether their activities in hypothyroid individuals were altered by acute and/or chronic thyroid hormone therapy. We have examined the substrate cycles between glucose and glucose6-phosphate, and between fructose-6-phosphate and fructose1,6-diphosphate.

\section{Methods}

These experiments involved three groups of subjects: $(a)$ normal volunteers, $(b)$ hyperthyroid patients, and $(c)$ hypothyroid patients. Patients were excluded from the study if they had other active medical illnesses or were taking medications. Their body dimensions and laboratory data are shown in Table I. All subjects gave informed 
consent. The protocol was reviewed and approved by the Massachusetts General Hospital Subcommittee on Human Studies.

Normal subjects. Four normal subjects, two males and two females, ages 35-50, served as controls.

Hyperthyroid patients. Five patients, two males and three females, ages 22-59. All had diffuse toxic goiter and typical clinical features of hyperthyroidism, including a recent history of heat intolerance and weight loss despite an increased appetite. All patients met chemical criteria for hyperthyroidism with elevated serum thyroxine $\left(T_{4}\right)^{1}(>12$ $\mu \mathrm{g} / \mathrm{dl}$ ) and triiodothyronine $\left(\mathrm{TT}_{3}\right)$ concentrations $(>195 \mathrm{ng} / \mathrm{dl})$.

Hypothyroid patients. Five patients, one male and four females, ages 30-74. All patients had clinical features of hypothyroidism, including cold intolerance and weight gain despite no change in appetite. They also met chemical criteria for hypothyroidism with a low serum thyroxine concentration $(<4.0 \mu \mathrm{g} / \mathrm{dl})$ and an elevated serum thyrotropin (TSH) concentration $(>3.5 \mu \mathrm{U} / \mathrm{ml})$.

The hypothyroid subjects were restudied after 1 wk of $50 \mu \mathrm{g} / \mathrm{d}$ parenteral sodium L-TT 3 (Sigma Chemical Co., St. Louis, MO) and again after $6 \mathrm{mo}$ of $100-150 \mu \mathrm{g} / \mathrm{d}$ of sodium L-thyroxine treatment (Flint-Travenol Laboratories, Deerfield, IL) when they were clinically and chemically euthyroid.

Procedure. All subjects were studied at 0800 after a $12 \mathrm{~h}$ overnight fast. An in-dwelling catheter was inserted into the right brachiocephalic vein and a blood sample was taken to determine the background enrichment of glucose. In six subjects (all four normal subjects and two hypothyroid patients [J.L. and R.F.]), a primed-constant infusion of a solution containing 2-deuterated; 2- $\mathrm{D}_{1^{-}}$, 3-deuterated; 3- $\mathrm{D}_{1^{-}}$, and 6,6-deuterated; 6,6- $\mathrm{D}_{2}$-glucose was then started. In all the remaining subjects only $2-D_{1}$ - and $6,6-D_{2}$-glucose were given. The primer consisted of a single bolus injection $(2 \mathrm{mg} / \mathrm{kg})$ of each tracer. The tracers were infused for $60 \mathrm{~min}$ at a rate of $0.019 \mathrm{mg} / \mathrm{kg} \cdot \min$ (pump rate 0.781 $\mathrm{ml} / \mathrm{min}$ ), except for 3-D-glucose, which was infused at a rate of 0.016 $\mathrm{mg} / \mathrm{kg} \cdot \mathrm{min}$. Blood samples were obtained from a vein in the left hand, which was placed in a thermostatically controlled chamber kept at $68^{\circ} \mathrm{C}$ to arterialize the blood (5). Over the first $45 \mathrm{~min}$ of isotope infusion, two 6-min collections of expired air were made in Douglas bags using a Rudolph 3-way valve for determination of oxygen consumption $\left(\dot{\mathrm{V}}_{2}\right)$ and carbon dioxide production $\left(\dot{\mathrm{VCO}}_{2}\right)$. Blood samples for the determination of the enrichment of glucose at the 2 , 3 , and 6 positions and subsequent calculations of glucose turnover and substrate cycling were obtained at $40,45,50,55$, and $60 \mathrm{~min}$ into the infusion. Insulin and glucagon determinations were performed on the 45- and 55-min samples. Previous experience indicated this length of infusion would be adequate to reach an isotopic plateau.

Stable isotopes. 2-D-glucose (90 atom percentage excess [APE]) was obtained from Cambridge Isotopes (Cambridge, MA). 3-D-glucose (97 APE) and 6,6-D - $\mathrm{D}_{2}$-glucose (98 APE) were obtained from Merck Isotopes (Montreal, Canada). The isotopes were dissolved in water passed through a 22- $\mu \mathrm{m}$ Amicon filter (Danvers, MA) and tested for sterility and pyrogens before infusion.

Analytical techniques. All blood samples were immediately placed on ice. Plasma was separated by centrifugation and stored frozen at $-30^{\circ} \mathrm{C}$ for subsequent analysis. Aliquots for glucagon analysis were placed in tubes with aprotinin and sodium EDTA. Serum glucose determinations were performed with a glucose autoanalyzer (Beckman Instruments, Inc., Fullerton, CA). Insulin and glucagon concentrations were determined by double antibody radioimmunoassays as previously described $(6,7)$. The oxygen, carbon dioxide, and nitrogen concentrations in the expired air were analyzed on a Perkin Elmer model 1100 medical gas analyzer (Wilton, CT). The volume was determined by

1. Abbreviations used in this paper: APE, atom percent excess; BMR, basal metabolic rate; $\mathrm{CI}$, chemical ionization; $2-\mathrm{D}_{1}, 3-\mathrm{D}_{1}$, and 6,6- $\mathrm{D}_{2}, 2-$, 3-, and 6,6-deuterated; EI, electron impact; $R a$, rate of appearance; SCR, substrate cycling rate; $T_{4}$, serum thyroxine; $T_{3}$, triiodothyronine; TSH, serum thyrotropin; TT3, triiodothyronine; $\mathrm{V}_{2}$, oxygen consumption; $\mathrm{VCO}_{2}$, carbon dioxide production. means of a gasometer (Warren Collins Co., Braintree, MA) and corrected to standard temperature and pressure, dry.

Gas-chromatography mass-spectrometry analysis of 2-D-, 3-D-, and 6,6-D - $D_{2}$ lucose

Analysis. All analyses were performed on a Hewlett-Packard 5985 quadrapole gas-chromatograph mass-spectrometer. Plasma glucose was initially separated as described previously (8) using Dowex AG1-X8 and AG-50W-X8 anion and cation ion exchange resins. The pentaacetyl derivative of glucose was formed by adding acetic anhydride and pyridine to the dried glucose sample, and heating at $100^{\circ} \mathrm{C}$ for 5 min. Approximately $1 \mu \mathrm{l}$ of the acetic anhydride solution was used for analysis.

A 3-ft glass coil packed with 3\% OV-101 was used for the chromatographic separation with the temperature programmed from $175^{\circ} \mathrm{C}$ to $250^{\circ} \mathrm{C}$ at a rate of $20^{\circ} \mathrm{C} / \mathrm{min}$. In the electron impact (EI) mode, helium carrier gas was used with a flow rate of $20 \mathrm{ml} / \mathrm{min}$. In the chemical ionization (CI) mode, methane was used both as the carrier and the reagent gas with a flow rate of $20 \mathrm{ml} / \mathrm{min}$. The retention time was $\sim 2 \mathrm{~min}$. Two anomeric peaks were observable and were integrated together or separately with identical results.

Since some of the samples contained three isotopic isomers with potential variation in enrichment at each position, all three positions in these samples were measured for each data point. The structure of the molecule and its resulting fragmentation patterns created a degree of interference in the analysis of each position from one or both of the other two. This interference was not alleviated by the use of the butyl-boronate or trimethylsilyl derivatives. Therefore, corrections for the interfering enrichments were made in the following manner: Both $(70 \mathrm{eV}) \mathrm{EI}$ ionization and methane $\mathrm{CI}$ were used to take advantage of particular fragments or enhanced signal abundances which occurred in each mode. The sum of the 2- $D_{1}$ - and 3-D $D_{1}$-glucose enrichments were measured by monitoring the ratio of the ion abundance at $\mathrm{m} / \mathrm{e}$ 116.1 to that at $\mathrm{m} / \mathrm{e} 115.1$ in the EI spectrum. The ionic fragment at mass 115.1 contains both the number 2- and 3-carbon of glucose, but it does not contain the number 6 -carbon. This was verified by analyzing the fragmentation patterns of the three infusates individually. The ion in the $\mathrm{CI}$ spectrum occurring at $\mathrm{m} / \mathrm{e} 169.1$ contains the 3- and the 6carbon, but does not contain the 2-carbon. Therefore, the 3- $D_{1}$-glucose $(M+1)$ value was measured by monitoring the $\mathrm{m} / \mathrm{e}$ ratio $170.1: 169.1$, and the 6- $\mathrm{D}_{2}$-glucose $(M+2)$ value was measured by monitoring the $\mathrm{m} / \mathrm{e}$ ratio of 171.1:169.1. A correction factor was applied for the interfering signal at $\mathrm{m} / \mathrm{e} 171.1$ created by the $3-\mathrm{D}_{1}$-glucose spectrum overlapping the 171.1 abundance of the $6-\mathrm{D}_{2}$-glucose spectrum. Similarly, the 170.1 value in the 3-D $D_{1}$-glucose measurement was corrected for the 170.1 overlap from the $6-D_{2}$-glucose spectrum. After determining the corrected value for the enrichment of the 3-D,-glucose molecule, this value was subtracted from the measured value at the $\mathrm{m} / \mathrm{e} 116.1$ to obtain the 2- $D_{1}$-glucose enrichment.

The APE of the labeled molecules is defined as the enrichment of the isotopic ion relative to the sum of all isotopic and nonisotopic ions at the same mass.

$\mathrm{APE}=(R /[R+1]) \times 100$, where $R$ is the ratio difference between the enriched and background (bkgrd) value normalized to 1. APE $=\frac{R}{R+1}(100 \%)=\left([m+a]_{\text {sample }}-[m+a]_{\text {bkerd }}\right) /\left([m+a]_{\text {sample }}-[m\right.$ $\left.+a]_{\text {bkgrd }}\right)+1(100 \%)$, where $a$ is $1,2,3$, etc. (depending on the number of mass units the isotopic ion is above the nonisotopic ion), $m+a$ is the mass of the isotopic ion, and $[m+a]$ is the abundance of the isotopic ion, $m+a$, relative to the nonisotopic ion, $m$, the latter being normalized to 1 .

Calculations. In all cases, a dynamic steady state was achieved in the enrichment of plasma glucose (Fig. 1). Therefore, the rate of appearance ( $\mathrm{Ra}$ ) for each isotope can be calculated as follows (9): 2$D_{1}$-glucose $\left(R_{2}\right)=$ (infusion rate of 2-D-glucose)/(IE 2-D-glucose) $\times 100,3-\mathrm{D}_{1}$-glucose $\left(\mathrm{Ra}_{3}\right)=$ (infusion rate of 3-D-glucose)/IE 3-Dglucose) $\times 100,6,6-D_{2}$-glucose $\left(R_{6}\right)=$ (infusion rate of 6- $\mathrm{D}_{2}$-glucose)/ IE 6- $\mathrm{D}_{2}$-glucose) $\times 100$, where $I E$ is the isotopic enrichment in APE. 
The rates of substrate cycling can be calculated as follows: substrate cycling rate (SCR) of glucose/glucose-6-phosphate $=\mathbf{R a}_{2}-\mathbf{R a}_{3} ; \mathbf{S C R}$ of fructose-6-phosphate/fructose-1,6-diphosphate $=\mathrm{Ra}_{3}-\mathrm{Ra}_{6}$; combined SCR between glucose/glucose-6-phosphate and between fructose6-phosphate/fructose-1,6-diphosphate $=R a_{2}-R_{a_{6}}$.

The statistical significance of differences between groups was calculated using the $t$ test. One way of analysis of variance was employed for analysis of serial data in the hypothyroid subjects before and after treatment.

\section{Results}

Pretreatment clinical and hormonal data. The ages, body dimensions, and clinical and laboratory findings in the normal, hypothyroid, and hyperthyroid subjects are summarized in Table $\mathrm{I}$. The mean fasting plasma glucose, insulin, and glucagon concentrations were the following: $97 \pm 13 \mathrm{mg} / \mathrm{dl}, 15 \pm 4 \mu \mathrm{U} /$ $\mathrm{ml}$, and $123 \pm 62 \mathrm{pg} / \mathrm{ml}$, respectively, in the normal subjects; $100 \pm 11 \mathrm{mg} / \mathrm{dl}, 24 \pm 6 \mu \mathrm{U} / \mathrm{ml}$, and $119 \pm 43 \mathrm{pg} / \mathrm{ml}$, respectively, in the hyperthyroid subjects; and $88 \pm 9 \mathrm{mg} / \mathrm{dl}, 15 \pm 4 \mu \mathrm{U} / \mathrm{ml}$, and $148 \pm 31 \mathrm{pg} / \mathrm{ml}$, respectively, in the hypothyroid subjects. Concentrations did not differ significantly among the three groups.

Pretreatment substrate cycling. A typical plasma enrichment time course for $2-D_{1}-, 3-D_{1}-$, and $6,6-D_{2}$-glucose in a subject during a primed-constant infusion of these tracers is shown in Fig. 1. After $40 \mathrm{~min}$, there was negligible variation in the enrichment of 2-- $D_{1-}-, 3-D_{1}-$, and 6,6- $D_{2}-$ glucose over the sampling period, and therefore, steady state conditions are applicable.

The turnover rates calculated using $2-\mathrm{D}_{1^{-}}, 3-\mathrm{D}_{1^{-}}, 6,6-\mathrm{D}_{2^{-}}$ glucose, and the oxygen consumption $\left(\mathrm{V}_{2}\right)$ and carbon dioxide production $\left(\dot{\mathrm{VCO}}_{2}\right)$ rates in the three study groups are shown

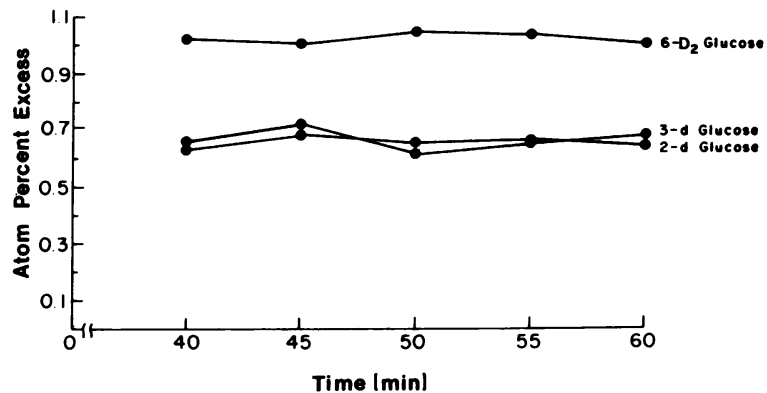

Figure 1. Representative enrichment time courses for 2-D-glucose, 3D-glucose, 6,6- $\mathrm{D}_{2}$-glucose from subject J.L. after a primed-constant infusion of 2-D-glucose, 3-D-glucose, 6,6- $\mathrm{D}_{2}$-glucose. Infusion rates for 2-D-glucose, 3-D-glucose, 6,6-D-glucose were $0.019,0.016,0.019 \mathrm{mg} /$ $\mathrm{kg} \cdot \min$, respectively.

in Table II. There was a significant decrease in the $\mathrm{Ra}_{2}$ and $\mathrm{Ra}_{6}$ in the hypothyroid group, their values being $1.77 \pm 0.56$ $\mathrm{mg} / \mathrm{kg} \cdot \min (P<0.01)$ and $1.57 \pm 0.31 \mathrm{mg} / \mathrm{kg} \cdot \min (P<0.05)$ respectively, compared with $3.23 \pm 0.56 \mathrm{mg} / \mathrm{kg} \cdot \mathrm{min}$ and $2.00 \pm 0.27 \mathrm{mg} / \mathrm{kg} \cdot \mathrm{min}$, respectively, in the euthyroid controls. In contrast, the hyperthyroid subjects had a significant increase in the mean $\mathrm{Ra}_{2}$ and $\mathrm{Ra}_{6}$ of $3.94 \pm 0.43 \mathrm{mg} / \mathrm{kg} \cdot \min (P<0.05)$ and $2.54 \pm 0.22 \mathrm{mg} / \mathrm{kg} \cdot \min (P<0.02)$, respectively, compared to the euthyroid controls.

The combined rates of SCR between glucose and glucose6-phosphate, and between fructose-6-phosphate and fructose1,6-diphosphate as determined by $\mathrm{Ra}_{2}-\mathrm{Ra}_{6}$ were $1.23 \pm 0.35$ $\mathrm{mg} / \mathrm{kg} \cdot \mathrm{min}$ in the normal group compared to significantly

Table I. Base-line Clinical and Laboratory Data, Normal, Hyperthyroid and Hypothyroid Subjects

\begin{tabular}{|c|c|c|c|c|c|c|c|}
\hline Subject & Age & Sex & Height & Weight & $\mathrm{T}_{4}$ & $\mathbf{T T}_{3}$ & TSH \\
\hline & & & $\mathrm{cm}$ & $k g$ & $\mu g / d l$ & $n g / d l$ & $\mu U / m l$ \\
\hline \multicolumn{8}{|l|}{ Euthyroid controls } \\
\hline B.W. & 35 & $\mathbf{M}$ & 196 & 86 & 8.7 & 126 & 1.9 \\
\hline P.L. & 35 & $\mathbf{M}$ & 178 & 84 & 7.1 & 105 & 2.8 \\
\hline J.P. & 53 & $\mathbf{F}$ & 165 & 64 & 7.7 & 147 & 2.5 \\
\hline D.G. & 50 & $\mathbf{F}$ & 155 & 50 & 9.9 & 121 & 0.5 \\
\hline Mean & 43 & & 174 & 71 & 8.4 & 125 & 1.9 \\
\hline$\pm \mathrm{SD}$ & \pm 10 & & \pm 18 & \pm 17 & \pm 1.2 & \pm 17 & \pm 1.0 \\
\hline \multicolumn{8}{|c|}{ Hyperthyroid patients } \\
\hline J.P. & 41 & $\mathbf{M}$ & 186 & 87 & 23.3 & 691 & $<0.5$ \\
\hline D.H. & 29 & $F$ & 182 & 66 & 21.5 & 575 & - \\
\hline M.C. & 27 & $\mathbf{F}$ & 165 & 58 & 22.8 & 577 & $<0.5$ \\
\hline L.S. & 26 & $\mathbf{F}$ & 146 & 54 & 21.8 & 568 & $<0.5$ \\
\hline T.K. & 59 & $\mathbf{M}$ & 175 & 61 & 30.2 & 566 & $<0.5$ \\
\hline Mean & 36 & & 171 & 65 & 23.9 & 595 & - \\
\hline$\pm \mathrm{SD}$ & \pm 14 & & \pm 16 & \pm 13 & \pm 3.6 & \pm 54 & - \\
\hline \multicolumn{8}{|c|}{ Hypothyroid patients } \\
\hline J.L. & 55 & $F$ & 167 & 64 & 1.4 & 37 & 28 \\
\hline D.D. & 39 & $\mathbf{M}$ & 158 & 76 & 1.1 & 43 & 116 \\
\hline R.F. & 42 & $\mathbf{F}$ & 162 & 50 & 0.2 & 25 & 242 \\
\hline J.F. & 54 & $\mathbf{F}$ & 165 & 89 & 2.0 & 73 & 115 \\
\hline D.B. & 74 & $\mathbf{F}$ & 151 & 49 & 0.1 & 5 & 156 \\
\hline Mean & 53 & & 161 & 66 & 1.0 & 37 & 131 \\
\hline \pm SD & \pm 14 & & \pm 6 & \pm 17 & \pm 0.8 & \pm 25 & \pm 78 \\
\hline Normal values & & & & & 4-12 & $70-185$ & $0.5-3.5$ \\
\hline
\end{tabular}


Table II. Metabolic Data: Normal, Hyperthyroid, and Hypothyroid Subjects

\begin{tabular}{|c|c|c|c|c|c|c|c|c|}
\hline Subject & $\mathbf{R a}_{\mathbf{2}}$ & $\mathbf{R a}_{3}$ & $\mathrm{Ra}_{6}$ & $\mathbf{R a}_{2}-\mathbf{R a}_{\mathbf{3}}$ & $\mathbf{R a}_{3}-\mathbf{R a}_{6}$ & $\mathbf{R a}_{2}-\mathbf{R} \mathbf{a}_{6}$ & $\dot{\mathrm{vO}}_{2}$ & $\dot{\mathrm{v}} \mathrm{CO}_{2}$ \\
\hline & $\mathrm{mg} / \mathrm{kg} \cdot \min$ & $m g / k g \cdot \min$ & $m g / k g \cdot \min$ & $m g / k g \cdot \min$ & $\mathrm{mg} / \mathrm{kg} \cdot \min$ & $m g / k g \cdot \min$ & $\mu \mathrm{mol} / \mathrm{kg} \cdot \min$ & $\mu \mathrm{mol} / \mathrm{kg} \cdot \min$ \\
\hline \multicolumn{9}{|c|}{ Euthyroid controls } \\
\hline B.W. & 3.81 & 2.81 & 2.38 & 1.00 & 0.43 & 1.43 & 123 & 88 \\
\hline P.L. & 3.05 & 1.90 & 1.93 & 1.15 & -0.03 & 1.12 & 147 & 112 \\
\hline J.P. & 3.53 & 2.83 & 1.96 & 0.70 & 0.87 & 1.57 & 158 & 118 \\
\hline D.G. & 2.53 & 3.00 & 1.74 & -0.47 & 1.26 & 0.79 & 146 & 130 \\
\hline Mean & 3.23 & 2.64 & 2.00 & 0.60 & 0.64 & 1.23 & 143 & 112 \\
\hline$\pm \mathrm{SD}$ & \pm 0.56 & \pm 0.50 & \pm 0.27 & \pm 0.73 & \pm 0.56 & \pm 0.35 & \pm 15 & \pm 18 \\
\hline \multicolumn{9}{|c|}{ Hyperthyroid patients } \\
\hline J.P. & 3.96 & & 2.52 & & & 1.44 & 230 & 165 \\
\hline D.H. & 3.28 & & 2.19 & & & 1.09 & 235 & 162 \\
\hline M.C. & 4.46 & & 2.74 & & & 1.72 & - & - \\
\hline L.S. & 3.88 & & 2.54 & & & 1.34 & 234 & 119 \\
\hline T.K. & 4.11 & & 2.73 & & & 1.38 & 227 & 163 \\
\hline Mean & $3.94^{*}$ & & $2.54 \ddagger$ & & & $1.39 \S$ & $238^{\prime \prime}$ & $165^{*}$ \\
\hline$\pm \mathrm{SD}$ & \pm 0.43 & & \pm 0.22 & & & \pm 0.23 & \pm 15 & \pm 35 \\
\hline \multicolumn{9}{|c|}{ Hypothyroid patients } \\
\hline J.L. & 1.21 & 1.25 & 1.31 & -0.04 & -0.06 & -0.10 & 98 & 71 \\
\hline D.D. & 1.28 & & 1.36 & & & -0.08 & - & - \\
\hline R.F. & 1.78 & 1.78 & 1.74 & 0 & 0.04 & 0.04 & 112 & 69 \\
\hline J.F. & 2.56 & & 1.40 & & & 1.16 & 85 & 69 \\
\hline D.B. & 2.04 & & 2.04 & & & 0 & 111 & 96 \\
\hline Mean & $1.77 \pi$ & 1.52 & $1.57^{* *}$ & -0.02 & -0.01 & $0.20 \ddagger \ddagger$ & $102 \ddagger$ & $76^{* *}$ \\
\hline$\pm \mathrm{SD}$ & \pm 0.56 & & \pm 0.31 & & & \pm 0.54 & \pm 13 & \pm 13 \\
\hline
\end{tabular}

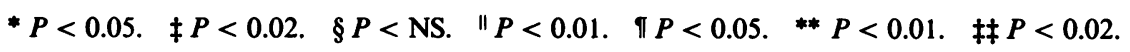

reduced rates of $0.20 \pm 0.54 \mathrm{mg} / \mathrm{kg} \cdot \min (P<0.02)$ in the hypothyroid group. The hyperthyroid group showed a higher but not significant increase in the combined SCR of $1.39 \pm 0.23$ $\mathrm{mg} / \mathrm{kg} \cdot \mathrm{min}$. In the two hypothyroid subjects in which 3-Dglucose was infused (J.L. and R.F.), the rates of substrate cycling in both cycles $\left(R_{2} a_{2}-R_{3}\right.$ and $\left.R a_{3}-R a_{6}\right)$ were each suppressed to approximately the same extent.

The mean $\dot{\mathrm{V}} \mathrm{O}_{2}$ and $\dot{\mathrm{V}} \mathrm{CO}_{2}$ rates were significantly reduced to $102 \pm 13 \mu \mathrm{mol} / \mathrm{kg} \cdot \min (P<0.02)$ and $76.0 \pm 13 \mu \mathrm{mol} / \mathrm{kg} \cdot \mathrm{min}$ $(P<0.05)$, respectively, in the hypothyroid group, and were significantly increased to $238 \pm 15 \mu \mathrm{mol} / \mathrm{kg} \cdot \min (P<0.01)$ and $165 \pm 35 \mu \mathrm{mol} / \mathrm{kg} \cdot \min (P<0.05)$, respectively, in the hyperthyroid group, as compared to $143 \pm 15 \mu \mathrm{mol} / \mathrm{kg} \cdot \mathrm{min}$ and $112 \pm 18 \mu \mathrm{mol} / \mathrm{kg} \cdot \mathrm{min}$, respectively, in the normal subjects.

Effect of acute and chronic thyroid hormone therapy in hypothyroid patients. The clinical and laboratory data for the hypothyroid subjects after 1 wk of parenteral triiodothyronine $50 \mu \mathrm{g} / \mathrm{d}$ are shown in Table III. The mean serum triiodothyronine concentration level rose significantly from a mean value of $37 \pm 25$ to $357 \pm 29 \mathrm{ng} / \mathrm{dl}(P<0.001)$, whereas the mean serum TSH levels fell significantly from $131 \pm 78 \mu \mathrm{U} / \mathrm{ml}$ to $2.0 \pm 1.1 \mu \mathrm{U} / \mathrm{ml}(P<0.05)$. The mean serum $\mathrm{T}_{4}$, fasting plasma glucose, insulin, and glucagon concentrations remained unchanged compared to pretreatment levels, the means being $1.0 \pm 0.9 \mu \mathrm{g} / \mathrm{dl}, 84 \pm 15 \mathrm{mg} / \mathrm{dl}, 15 \pm 9 \mu \mathrm{U} / \mathrm{ml}$, and $124 \pm 48 \mathrm{pg} /$ $\mathrm{ml}$, respectively. The mean $\dot{\mathrm{VO}}_{2}$ and $\mathrm{VCO}_{2}$ both increased significantly from their pretreatment levels, $102 \pm 13 \mu \mathrm{mol} /$ $\mathrm{kg} \cdot \mathrm{min}$ and $76 \pm 13 \mu \mathrm{mol} / \mathrm{kg} \cdot \mathrm{min}$, respectively, to $147 \pm 34$ $\mu \mathrm{mol} / \mathrm{kg} \cdot \min (P<0.05)$ and $111 \pm 19 \mu \mathrm{mol} / \mathrm{kg} \cdot \min (P<0.05)$, respectively (Table IV). However, $\mathrm{Ra}_{2}$ and $\mathrm{Ra}_{6}$ were unchanged with no resultant change in the substrate cycling rates.
Table III. Clinical and Laboratory Data:

Hypothyroid Patients After Treatment with Triiodothyronine* and After Treatment with L-Thyroxine

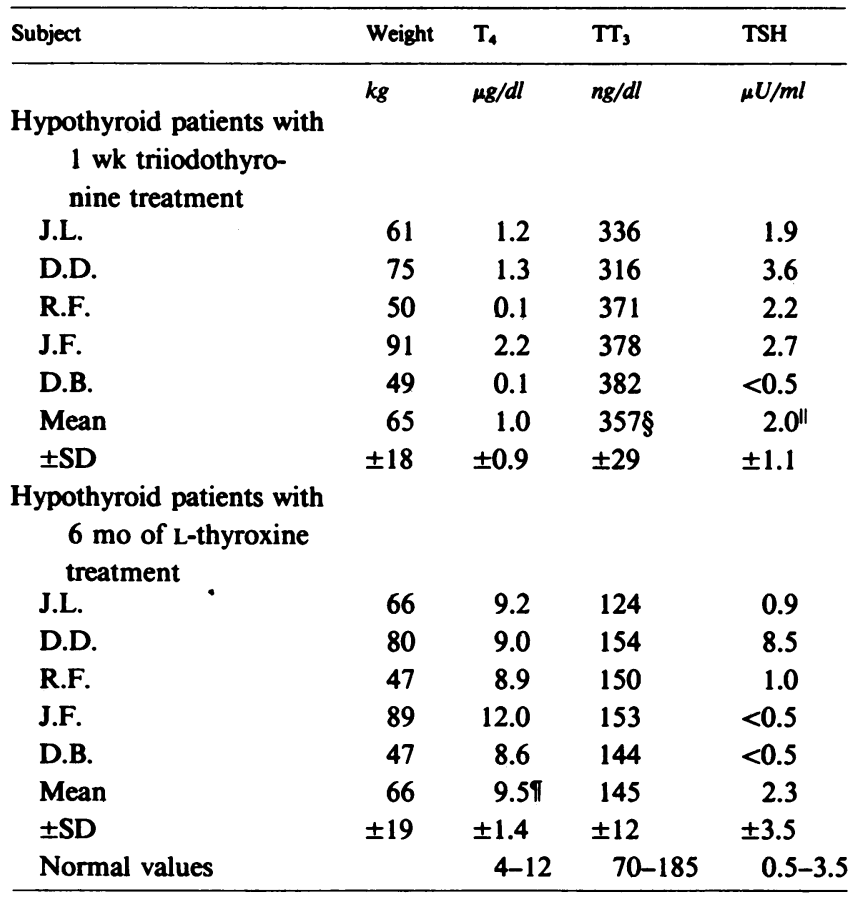

* $50 \mu \mathrm{g} / \mathrm{d} \times 1 \mathrm{wk}$.

$\ddagger 100-150 \mu \mathrm{g} / \mathrm{d} \times 6 \mathrm{mo}$.

$\S P<0.001$ before vs. after 1 wk triiodothyronine treatment.

" $P<0.05$ before vs. after 1 wk triiodothyronine treatment.

II $P<0.01$ before vs. after 6 mo L-thyroxine treatment. 
Table IV. Metabolic Data: Hypothyroid Subjects After Treatment with Triiodothyronine $(50 \mu \mathrm{g} / \mathrm{dl} \times 1 \mathrm{wk})$ and After Treatment with Thyroxine $(100-150 \mu \mathrm{g} / \mathrm{d} \times 6 \mathrm{mo})$

\begin{tabular}{|c|c|c|c|c|c|c|c|c|}
\hline Subject & $\mathbf{R a}_{2}$ & $\mathbf{R a}_{3}$ & $\mathbf{R a}_{6}$ & $\mathbf{R a}_{2}-\mathbf{R a}_{3}$ & $\mathrm{Ra}_{3}-\mathrm{Ra}_{6}$ & $\mathbf{R a}_{2}-\mathbf{R a}_{6}$ & $\dot{\mathrm{vO}}_{2}$ & $\dot{\mathrm{v}} \mathrm{CO}_{2}$ \\
\hline & $m g / k g \cdot m i n$ & $\mathrm{mg} / \mathrm{kg} \cdot \min$ & $\mathrm{mg} / \mathrm{kg} \cdot \min$ & $\mathrm{mg} / \mathrm{kg} \cdot \min$ & $m g / k g \cdot \min$ & $\mathrm{mg} / \mathrm{kg} \cdot \min$ & $\mu \mathrm{mol} / \mathrm{kg} \cdot \min$ & $\mu \mathrm{mol} / \mathrm{kg} \cdot \min$ \\
\hline \multicolumn{9}{|c|}{$\begin{array}{l}\text { Hypothyroid patients after } \\
1 \text { wk triiodothyro- } \\
\text { nine treatment }\end{array}$} \\
\hline J.L. & 1.12 & 1.10 & 1.31 & 0.02 & -0.21 & -0.19 & 150 & 110 \\
\hline D.D. & 1.55 & & 1.54 & & & 0.01 & & \\
\hline R.F. & 1.47 & 1.51 & 1.62 & -0.04 & -0.11 & -0.15 & 183 & 130 \\
\hline J.F. & 2.45 & & 1.73 & & & 0.72 & 100 & 85 \\
\hline D.B. & 2.16 & & 2.20 & & & -0.04 & 154 & 119 \\
\hline Mean & $1.75^{*} \S$ & 1.30 & $1.68 * \S$ & -0.01 & -0.16 & $0.07 \S$ & $147 \ddagger \S$ & $111 \ddagger \S$ \\
\hline$\pm \mathrm{SD}$ & \pm 0.54 & & \pm 0.33 & & & \pm 0.37 & \pm 34 & \pm 19 \\
\hline \multicolumn{9}{|c|}{$\begin{array}{l}\text { Hypothyroid patients after } \\
6 \text { mo of L-thyroxine } \\
\text { treatment }\end{array}$} \\
\hline J.L. & 2.91 & 2.48 & 1.90 & 0.43 & 0.58 & 1.01 & 130 & 107 \\
\hline D.D. & 2.81 & & 1.84 & & & 0.97 & & \\
\hline R.F. & 3.11 & 2.51 & 2.11 & 0.60 & 0.40 & 1.00 & 178 & 128 \\
\hline J.F. & 2.87 & & 2.00 & & & 0.87 & 122 & 93 \\
\hline D.B. & 2.75 & & 2.29 & & & 0.46 & 130 & 108 \\
\hline Mean & $2.89^{11 * *}$ & 2.50 & $2.03 \pi^{* *}$ & 0.52 & 0.49 & $0.86^{11 * *}$ & $135^{* * *}$ & $110^{* * *}$ \\
\hline$\pm \mathrm{SD}$ & 0.14 & & \pm 0.18 & & & \pm 0.23 & \pm 25 & \pm 12 \\
\hline
\end{tabular}

* $P<$ NS. $\ddagger P<0.05$. § Before vs. after 1 wk triiodothyronine treatment. " $P<0.02 . \quad$ I $P<0.01 . \quad * *$ Before vs. after 6 mo thyroxine treatment.

After 6 mo of $T_{4}$ treatment, normalization of the serum $\mathrm{T}_{4}$ and $\mathrm{TT}_{3}$ levels was documented in all of the hypothyroid subjects (Table III). The mean fasting plasma glucose, insulin, and glucagon levels remained unchanged at $93 \pm 6 \mathrm{mg} / \mathrm{dl}, 16 \pm 7$ $\mu \mathrm{U} / \mathrm{ml}$, and $107 \pm 63 \mathrm{pg} / \mathrm{ml}$, respectively, compared with both the pretreatment values and those obtained after 1 wk of parenteral $\mathrm{T}_{3}$ treatment. The $\dot{\mathrm{V}} \mathrm{O}_{2}$ and $\dot{\mathrm{V}} \mathrm{CO}_{2}$ rates also remained unchanged compared to their levels obtained 1 wk after $T_{3}$ treatment (Table 4). The increase in serum $\mathrm{T}_{4}$ was paralleled by a significant increase in $\mathrm{Ra}_{2}$ to $2.89 \pm 0.14 \mu \mathrm{mol} / \mathrm{kg} \cdot \mathrm{min}(P$ $<0.02)$ and $\mathrm{Ra}_{6}$ to $2.03 \pm 0.18 \mu \mathrm{mol} / \mathrm{kg} \cdot \min (P<0.01)$ (Table IV) compared to the values obtained before treatment. The posttreatment $R a_{2}$ and $R a_{6}$ values were not significantly different from the mean levels in the normal control group (Table I). The mean combined rate of substrate cycling increased significantly to $0.86 \pm 0.23 \mathrm{mg} / \mathrm{kg} \cdot \min$ (Table IV) compared to 1 wk after $\mathrm{T}_{3}$ treatment, $0.07 \pm 0.37 \mathrm{mg} / \mathrm{kg} \cdot \min (P<0.02)$. It was not significantly different from the combined rate of substrate cycling observed in the normal subjects of $1.23 \pm 0.35$ $\mathrm{mg} / \mathrm{kg} \cdot \mathrm{min}$ (Table II).

\section{Discussion}

We have studied substrate cycling rates between glucose and glucose-6-phosphate, and between fructose-6-phosphate and fructose-1,6-diphosphate in euthyroid, hypothyroid, and hyperthyroid man determined by differences in steady state appearance rates of $2-D_{1}$-glucose, $3-D_{1}$-glucose and $6,6-D_{2}-$ glucose. We have found the following: $(a)$ these cycles existed in normal man and could be detected using a stable isotope technique; $(b)$ the combined rate of these two substrates cycles was significantly less in hypothyroid patients than in normal subjects; $(c)$ the rate of these two substrate cycles tended to be higher in hyperthyroid subjects compared to normal subjects; (d) despite normalization of the $\dot{\mathrm{V}} \mathrm{O}_{2}$ and $\dot{\mathrm{V}} \mathrm{CO}_{2}$ after 1 wk of parenteral L-triiodothyronine treatment $(50 \mu \mathrm{g} / \mathrm{d})$ in the hypothyroid subjects, the rate of substrate cycling between these two steps remained low (5). After 6 mo of L-thyroxine treatment $(100-150 \mu \mathrm{g} / \mathrm{d})$ in these same subjects and attainment of euthyroid indices, the substrate cycling rates between these two steps returned to normal.

The concept that glycolytic enzymes are completely suppressed during active gluconeogenesis has recently been questioned because of the demonstration of glucose/glucose-6phosphate (10) and fructose-6-phosphate/fructose-1,6-diphosphate cycles in liver (11). Newsholme and Underwood (1) were the first to propose a role of substrate cycling in providing flexibility of metabolic regulation and thermogenesis. They also proposed that substrate cycling may be under hormonal control enabling hormones to alter the magnitude of tissue responses to a metabolic signal without changing the biochemistry of the basic control mechanisms (2).

To approximate the SCRs, we employed a labeled substrate that undergoes a site specific transformation that persists after recycling. This technique has already been used successfully in vitro $(3,4)$ and in vivo $(12-26)$. Since deuterium at position 2 of glucose is cleaved at the level of the phosphoglucose isomerase step, most $D_{2}$ will be removed before glucose-6phosphate leaves to become either glycogen or plasma glucose (27). The deuterium at position 3 of glucose appears on the $\mathrm{C}_{1}$ of dihydroxyacetone phosphate and is cleaved during the isomerization to glyceraldehyde-3-phosphate (28). A glucose molecule that cycles through the glucose/glucose-6-phosphate cycle, but not through the fructose-6-phosphate/fructose-1,6- 
diphosphate cycle, will lose the deuterium at position 2 but not the deuterium from position 3. Thus, the difference between $\mathrm{Ra}_{2}$ and $\mathrm{Ra}_{3}$ serves as an index of substrate cycling between glucose and glucose-6-phosphate. Similarly, the deuterium from position 6 at glucose is replaced during carboxylation of pyruvate into oxoloacetate, and equilibration with dicarboxylic acids (3). The Ra measured by means of $6,6-2^{-}$ glucose will include molecules that have cycled through glucose/ glucose-6-phosphate or fructose-6-phosphate/fructose-1,6-diphosphate. Therefore, the difference between $\mathrm{Ra}_{3}$ and $\mathrm{Ra}_{6}$ can be used to assess the SCR between fructose-6-phosphate and fructose-1,6-diphosphate. The difference between $\mathrm{Ra}_{2}$ and $\mathrm{Ra}_{6}$ reflects the combined SCR between glucose and glucose-6phosphate, and between fructose-6-phosphate and fructose1,6-diphosphate.

Both of these calculations rely on the following assumptions: (a) nonenzymatic exchange of the deuterated label does not occur; that $(b)$ the hexose isomerase and triose isomerase steps operate at a rate much faster than the net flux; and that $(c)$ the pentose pathway in the liver operates at a negligible rate compared to the total flux of glucose down the glycolytic pathway. With regard to the first of these assumptions, in vivo studies have demonstrated that the difference between the slopes of the specific activities of plasma glucose after intravenous injection of either $\left[2-{ }^{3} \mathrm{H}\right]$ glucose or $\left[1-{ }^{14} \mathrm{C}\right]$ glucose is abolished by evisceration and nephrectomy (29). This suggests that the difference observed in normal rats is due to the reincorporation of ${ }^{14} \mathrm{C}$ atoms into newly released glucose and not to a nonmetabolic tritium-proton exchange of plasma glucose. In regard to the second assumption, while it is unlikely that the rate of phosphohexose isomerase is rapid enough to cause complete loss of the 2-d label at the glucose-6-phosphate level, it is probable that this reaction is fast enough to cause almost complete exchange (4). That the rate of the isomerase steps greatly exceeds net flux is supported by the observations of Katz and Rognstad (6), who injected rats with 2-tritiatedglucose and found that the label was promptly lost and virtually completely recovered in body water. To the extent that the $2 \mathrm{~d}$ is not lost and there is recycling of 2-D-glucose, then, the calculation of glucose/glucose-6-phosphate recycling by $\mathbf{R a}_{2}-\mathbf{R a}_{3}$ would underestimate the rate at this step. In analogous fashion, the calculation of the SCR between fructose6-phosphate and fructose-1,6-diphosphate relies on the assumption that triose phosphate isomerase operates much more rapidly than the net flux, and that the aldolase reaction is rapid and readily reversible. In support of these assumptions, it has been shown that the exchange of hydrogens from positions 3, 4, and 5 of glucose is more extensive than the one occurring during the reaction catalyzed by the phosphoglucose isomerase, and that the retention of tritium in fructose diphosphate is small (30).

Finally, the calculation of the SCR between glucose/glucose6-phosphate assumes that there is only minimal activity of the pentose cycle pathway and that this is not significantly altered by thyroid hormone treatment. Any activity of this cycle will cause additional loss of deuterium from the 2-position of glucose and lead to an overestimation of the SCR between glucose and glucose-6-phosphate. It has been calculated that $\sim 8 \%$ of glucose is metabolized by the hexose monophosphate pathway in man (31) and that this activity was not altered in hepatocytes taken from $T_{3}$-treated rats (32).
In summary, these data support the reliability of our observations of hepatic substrate cycling based upon this technique and its inherent assumptions.

$R_{2}$ and $R_{6}$ were less in the hypothyroid patients and greater in the hyperthyroid patients compared to the normal subjects (Table II). These observations are in accord with those of Saunders et al. (33) and McCulloch et al. (34) who found that glucose turnover rates as determined by $\left[3-{ }^{3} \mathrm{H}\right]$ glucose infusions were significantly increased in hyperthyroid subjects and decreased in hypothyroid subjects compared to normal. Our observations are also in agreement with the rat studies of Ui and Okajima (17), in which the turnover rates of $\left[2-{ }^{3} \mathrm{H}\right]-$ and $\left[6-{ }^{3} \mathrm{H}\right]$ glucose were found to be increased in rats made hyperthyroid by daily injections of L-thyroxine and decreased in rats made hypothyroid by treatment with methylthiouracil.

The combined SCR was significantly lower in our hypothyroid subjects. In two of the hypothyroid subjects the individual cycles were shown to be equally suppressed and essentially nondetectable during hypothyroidism (Table II). These results are also in agreement with those of $\mathrm{Ui}$ and Okajima (17) who found that substrate cycling as assessed by differences in replacement rates of $\left[2-{ }^{3} \mathrm{H}\right]$ glucose and $\left[6-{ }^{3} \mathrm{H}\right]$ glucose was significantly decreased in hypothyroid rats. These workers also found a significant increase in these substrate cycles in their hyperthyroid-induced rats, whereas our hyperthyroid patients had a slight but not significant increase in their combined SCR. This difference might reflect a species difference, a difference between response in spontaneous and experimental hyperthyroidism, or a more severely hyperthyroid state. In man, McCulloch et al. (34) also found an increase in glucose recycling in thyrotoxicosis and a decrease in recycling in primary thyroid failure as assessed by measuring the difference in turnover rates of $\left[3-{ }^{3} \mathrm{H}\right]$ glucose and $\left[1-{ }^{14} \mathrm{C}\right]$ glucose. However, this technique does not distinguish between intrahepatic substrate cycling and cycling that occurs between the liver and the periphery (i.e., glucose-alanine, glucose-lactate). Furthermore, since the tritium in the third position is lost at the level of the triose isomerase step, this technique does not include recycling between glucose and glucose-6-phosphate.

Our value for the combined SCR in normal subjects as defined by $R_{2} a_{2}-R_{6}$ is comparable to the value found by Altszuler et al. (12) in normal dogs, assuming $\mathrm{Ra}\left[6-{ }^{14} \mathrm{C}\right]$ glucose (corrected for recycling) is approximately equal to $\mathrm{Ra}, 6,6-\mathrm{D}_{2}$ glucose. However, our values for the differences between $\mathbf{R a}_{2}$ - $R a_{3}$ and $R a_{3}-R a_{6}$ may be higher than those previously found. Several studies $(12,15,17,35)$ in animals have found significant differences in turnover rates between $R a_{2}$ and $R a_{3}$, whereas another study in man could find only a very small difference (36). Similarly, some studies done in animals have been able to detect differences in turnover rates between $\mathbf{R a}_{3}$ and $\mathrm{Ra}_{6}$ (17), whereas others could detect little or none (12, $15,35)$. The differences between our results and some of those in the literature may reflect species variation although this would not explain the discrepancy between our results and those of Efendic et al. (36). It is also possible that methodological discrepancies are responsible for some of these reported differences, since both the radioactive technique and the stable isotope technique have potential limitations. The tritium label technique relies on chemical separation, or in doing the different isotope infusions in the same subject on different days. In contrast to the radioisotope technique, the stable 
isotope technique distinguishes the label on the various species without ambiguity, but the amount of radioactive glucose present can be more accurately determined than the isotopic enrichment of stable isotopes, particularly when all three stable isotopes are present simultaneously. For these reasons, and the small number of subjects infused with 3-D-glucose, we have based all of our conclusions on the $\mathrm{Ra}_{2}-\mathrm{Ra}_{6}$ data, and have not made any conclusions about the separate rates of the two substrate cycles included in that value. Nonetheless, it is worth noting that in the two hypothyroid subjects in whom 3-Dglucose was infused there was no difference between $\mathrm{Ra}_{3}$ and $\mathrm{Ra}_{6}$, whereas in the two controls the difference was $0.56 \mathrm{mg} /$ kg. min (Table I).

The mechanism(s) underlying changes in the SCRs in hypo- and hyperthyroidism remain to be established. These changes could not be accounted for by variations in the major glucoregulatory hormones insulin and glucagon. It has been shown that the activity of glucose-6-phosphate is decreased in hypothyroid rats (37) and that the activities of both glucokinase (38) and glucose-6-phosphatase (37) are increased in the hyperthyroid state (although the activity of the latter enzyme has also been reported to be decreased in the hyperthyroid state) (38). It is, therefore, plausible that similar changes might occur for phosphofructokinase and fructose-1,6-diphosphatase.

Since heat production owing to ATP dissipation occurs during operation of substrate cycling, it has been hypothesized that substrate cycling may account for a significant fraction of the basal metabolic rate (BMR). Alterations in substrate cycling in hypo- and hyperthyroid patients might be partially responsible for some of the calorigenic effects of thyroid hormone. The rate of heat production from substrate cycling can be estimated from the equation $\mathrm{d} h_{\mathrm{t}} / \mathrm{d} t=h_{\mathrm{t}} n c$, where $h_{\mathrm{t}}$ is the heat released by the hydrolysis of $1 \mathrm{~mol}$ of ATP and rephosphorylation of $1 \mathrm{~mol}$ of ADP, $n$ is the number of ATP molecules hydrolyzed to ADP per revolution of the cycle, and $c$ is the rate of cycling in moles/unit time (2). It has been shown that for each mole of ATP synthesized and hydrolyzed, $17.4 \mathrm{kcal}$ of heat are released when the substrate is carbohydrate (2). It can be approximated that the decrease in SCR observed in the hypothyroid patients can account for $\sim 20 \mathrm{kcal} / \mathrm{d}(17.4 \mathrm{kcal} /$ mol ATP $\times 2 \times 0.556 \mathrm{~mol} \mathrm{ATP} / \mathrm{d})$.

Whereas this accounts for $<2 \%$ of the total basal metabolic rate, this quantity of heat represents the amount of energy generated from only two hepatic substrate cycles in the basal state. Since there are several possible substrate cycles, not only in the liver but in muscle and other tissues, it is conceivable that substrate cycling may account for a significant fraction of the BMR. After 1 wk of acute $T_{3}$ therapy, $R a_{2}, R_{3}$, and $R a_{6}$ were unchanged in the hypothyroid subjects despite significantly elevated $\mathrm{T}_{3}$ levels (Tables III and IV). In contrast, their $\dot{\mathrm{V}} \mathrm{O}_{2}$ and $\mathrm{VCO}_{2}$ both normalized with this treatment. This suggests that these two cycles by themselves do not contribute significantly to the total BMR, and is in agreement with our calculations as stated above. However, it does not rule out the possibility that other substrate cycles exist that do normalize acutely and contribute to normalization of the overall BMR. Indeed, the phosphoenolpyruvate substrate cycle, measured by ${ }^{13} \mathrm{C}$ nuclear magnetic resonance techniques, in isolated rat hepatocytes has been shown to be regulated by thyroid hormone such that after 1 wk of $T_{3}$ treatment there was a $35 \%$ increase in the SCR (39). After 6 mo of $T_{4}$ treatment and establishment of the euthyroid state in the hypothyroid group, $\mathbf{R a}_{2}, \mathbf{R a}_{3}$, and $\mathrm{Ra}_{6}$, the calculated rates of substrate cycling were all normalized.

We conclude that substrate cycling between glucose and glucose-6-phosphate and between fructose-6-phosphate and fructose-1,6-diphosphate occurs in man and is affected in part by thyroid hormone. This effect is independent of the other major glucoregulatory hormones-insulin and glucagon. Substrate cycles may represent a mechanism by which thyroid hormone alters the sensitivity of certain reactions to metabolic signals. The mechanism behind these changes in substrate cycling remains to be elucidated.

\section{Acknowledgments}

The authors are very grateful to Jean Piazza, Marion D'Amato, and the other nurses and staff of the General Clinical Research Center at the Massachusetts General Hospital for their assistance with these clinical studies. We would also like to thank Rita Lee for technical assistance with the hormone radioimmunoassays and Judy Chadwick and Nancy Patterson for their typing of this manuscript.

This work was supported in part by grants RR-1066, RR-00073, AM-16791, HL-07354, AM-34817, and AM-01248 from the National Institutes of Health and a grant from the Shriners Hospital.

\section{References}

1. Newsholme, E. A., and W. Gevers. 1967. Control of glycolysis and gluconeogenesis in liver and kidney cortex. Vitam. Horm. 25:187.

2. Newsholme, E. A., and B. Crabtree. 1976. Substrate cycles in metabolic regulation and in heat generation. Biochem. Soc. Symp. 41: 61-109.

3. Hue, H. 1980. The role of futile cycles in the regulation of carbohydrate metabolism in the liver. Adv. Enzymol. 52:247-331.

4. Katz, J., and R. Rognstad. 1976. Futile cycles in the metabolism of glucose. Curr. Top. Cell. Regul. 10:237-289.

5. Abumrad, M. N., D. Rabin, M. P. Diamond, and W. M. Lacy. 1981. Use of a heated superficial hand vein as an alternate site for the measurement of amino acid concentrations and for the study of glucose and alanine kinetics in man. Metab. Clin. Exp. 30:936-940.

6. Albano, J. D. M., R. P. Ekins, G. Maritz, and R. C. Turner. 1972. A sensitive precise radioimmunoassay of serum insulin recycling on charcoal separation of bound and free hormone moieties. Acta Endocrinol. 60:487-509.

7. Faloona, S. R., and R. H. Unger. 1981. Glucagon. In Methods of Hormone Radioimmunoassay. B. M. Jaffe and H. R. Berhman, editors. Academic Press, Inc., New York. 317-330.

8. Wolfe, R. R., T. F. O'Donnell, Jr., M. D. Stone, D. A. Richmand, and J. F. Burke. 1980. Investigation of factors determining the optimal glucose infusion rate in total parenteral nutrition. Metab. Clin. Exp. 29:892-900.

9. Searle, G. L., E. H. Strisower, and I. L. Chaikoff. 1954. Glucose pool and glucose space in normal and diabetic dog. Am. J. Physiol. 176:190-194.

10. Clark, D. G., R. Rognstad, and J. Katz. 1973. Isotopic evidence for futile cycles in liver cells. Biochem. Biophys. Res. Commun. 54: 1141-1148.

11. Clark, D. G., D. Lee, R. Rognstad, and J. Katz. 1975. Futile cycles in isolated perfused rat liver and in isolated rat liver parenchymal cells. Biochem. Biophys. Res. Commun. 67:212-219.

12. Altszuler, M., A. Barkai, C. Bjerknes, G. Gottlieb, and R. Steele. 1975. Glucose turnover values in the dog obtained with various species of labeled glucose. Am. J. Physiol. 229:1662-1667.

13. Issekutz, B., Jr., M. Allen, and I. Borkow. 1972. Estimation of 
glucose turnover in the dog with glucose-2-t and glucose-U $-{ }^{14} \mathrm{C} . A m$. J. Physiol. 222:710-712.

14. Issekutz, B., Jr. 1977. Studies of hepatic glucose cycles in normal and methylprednisolone-treated dogs. Metab. Clin. Exp. 26: 157-170.

15. Dunn, A., J. Katz, S. Golden, and M. Chenoweth. 1976. Estimation of glucose turnover and recycling in rabbits using various ${ }^{3} \mathrm{H},{ }^{14} \mathrm{C}$-glucose labels. Am. J. Physiol. 230:1159-1162.

16. Dunn, A., and M. Chenoweth. 1979. Fructose-6-phosphate substrate cycling and glucose and insulin regulation of gluconeogenesis in vivo. Am. J. Physiol. 236:E410-E415.

17. Ui, M., and F. Okajima. 1979. Metabolism of glucose in hyperand hypothyroid rats in vivo. Biochem. J. 182:565-575.

18. Anwer, M. S., T. E. Chapman, and R. Gronwall. 1976. Glucose utilization and recycling in ponies. Am. J. Physiol. 230:138-142.

19. Chenoweth, M., and A. Dunn. 1978. Fructose-6-phosphate substrate cycling and hormonal regulation of gluconeogenesis in vivo. Am. J. Physiol. 235:E295-E303.

20. Katz, J., A. Dunn, M. Chenoweth, and S. Golden. 1974. Determination of synthesis recycling and body mass of glucose in rats and rabbits in vivo with ${ }^{3} \mathrm{H}$ - and ${ }^{14} \mathrm{C}$-labeled glucose. Biochem. J. 142: 171-183.

21. Stevenson, R. W., J. A. Parsons, and K. G. M. M. Alberti. 1983. Effect of intraportal and peripheral insulin on glucose turnover and recycling in diabetic dogs. Am. J. Physiol. 244:E190-E195.

22. Clark, M. G., D. P. Bloxham, P. C. Holland, and H. A. Hardy. 1973. Estimation of the fructose diphosphatase-phosphofructokinase substrate cycle in the flight muscle of bombus affinis. Biochem. J. 134: 589-597.

23. Clark, M. G., D. P. Bloxham, P. C. Holland, and H. A. Hardy. 1974. Estimation of the fructose-1,6-diphosphatase-phosphofructokinase substrate cycle and its relationship to gluconeogenesis in rat liver in vivo. 249:279-290.

24. Brady, L. J., D. R. Romsos, and G. A. Leveille. 1977. Glucose turnover in the young chicken (Gallus domesticus) using variously labeled $\left[{ }^{3} \mathrm{H}, \mathrm{U}-{ }^{14} \mathrm{C}\right]$-glucose tracers. Comp. Biochem. Physiol. 56:421425.

25. Surholt, B., and E. A. Newsholme. 1983. The rate of substrate cycling between glucose and glucose-6-phosphate in muscle and fat body of the hawk moth (Acheronita atropos) at rest and during flight. Biochem. J. 210:49-54.

26. Tserng, K., and S. Kalhan. 1983. Estimation of glucose carbon recycling and glucose turnover with $\mathrm{U}^{-13} \mathrm{C}$-glucose. Am. J. Physiol. 245:E476-E482.

27. Katz, J., and A. Dunn. 1967. Glucose-2-t as a tracer for glucose metabolism. Biochemistry. 6:1-5.

28. Hue, L., and H. Hers. 1974. On the use of ${ }^{3} \mathrm{H},{ }^{14} \mathrm{C}$-labeled glucose in the study of the so called "futile cycles" in the liver and muscle. Biochem. Biophys. Res. Commun. 58:532-539.

29. Hetenyi, G., Jr., and D. Mak. 1970. ${ }^{3} \mathrm{H}-2$-glucose as a tracer in turnover studies. Can. J. Physiol. Pharmacol. 48:732-734.

30. Rose, I. D. 1970. Enzymology of proton abstraction and transfer reactions. In The Enzymes. P. D. Boyer, editor. Academic Press, Inc., New York. Third ed. 2:281-320.

31. Segal, S., M. Berman, and A. Blair. 1962. The metabolism of various ${ }^{14} \mathrm{C}$-labeled glucose in man and an estimation of the extent of glucose metabolism by the hexose monophosphate pathway. J. Clin. Invest. 1:1263-1279.

32. Cohen, S. M., S. Ogawa, and R. G. Shulman. 1979. ${ }^{13} \mathrm{C}$ NMR studies of gluconeogenesis in rat liver cells: utilization of labeled glycerol by cells from euthyroid and hyperthyroid rats. Proc. Natl. Acad. Sci. USA. 76:1603-1607.

33. Saunders, J., S. E. H. Hall, and P. M. Sonksen. 1980. Glucose and free fatty acid turnover in thyrotoxicosis and hypothyroidism: before and after treatment. Clin. Endocrinol. 13:33-44.

34. McCulloch, A. J., R. Nosadini, A. Pernet, M. Pinjewska, D. B. Cook, F. Clark, D. C. Johnston, and K. G. M. M. Alberti. 1983. Glucose turnover and indices of recycling in thyrotoxicosis and primary thyroid failure. Clin. Sci. 64:41-47.

35. Katz, J., S. Golden, A. Dunn, and M. Chenoweth. 1976. Estimation of glucose turnover in rats in vivo with tritium labeled glucose. Z. Physiol. Chem. 357:1387-1394.

36. Efendic, S., A. Wajngot, and M. Vranic. 1983. Hepatic futile cycle is an important metabolic pathway in lean type-2 diabetics. Diabetes. 32(Suppl.):72A. (Abstr.)

37. Battarbee, H. D. 1974. The effects of thyroid state on rat liver glucose-6-phosphatase activity and glycogen content. Proc. Soc. Exp. Biol. Med. 147:337-343.

38. Winnick, S. 1970. Response of hepatic glucokinase and glucose6-phosphatase activities in juvenile and adult hyperthyroid mice. Endocrinology. 87:124-128.

39. Cohen, S. M., P. Glynn, and R. G. Shulman. $1981 .{ }^{13} \mathrm{C}$ NMR study of gluconeogenesis from labeled alanine in hepatocytes from euthyroid and hyperthyroid rats. Proc. Natl. Acad. Sci. USA. 78:6064. 